\title{
SSynthesis
}

International Scientific Conference of IT and Business-Related Research

\section{KOMPLEKSNOST TURISTIČKOG PROIZVODA KAO FAKTOR KONKURENTNOSTI BANJSKIH DESTINACIJA}

\author{
THE COMPLEXITY OF TOURISM PRODUCTS AS A FACTOR \\ OF SPA DESTINATION COMPETITIVENESS \\ Milena Podovac ${ }^{1}$, Melita Jovanović Tončev ${ }^{2}$ \\ ${ }^{1}$ Univerzitet u Kragujevcu, Fakultet za hotelijerstvo i turizam, Vrnjačka Banja, Srbija \\ ${ }^{2}$ Univerzitet Singidunum, Beograd, Srbija
}

\begin{abstract}
Apstrakt:
Formiranje turističkog proizvoda predstavlja jedan od najvažnijih zadataka subjekata koji učestvuju u oblikovanju ponude konkretne destinacije. Uzimajući u obzir stalne promene potreba turističke tražnje, neophodno je ponuditi proizvod, koji će za turistu imati dodatnu vrednost. U cilju postizanja konkurentnosti na evropskom tržištu, banje Srbije se nalaze pred izazovom kreiranja integrisane turističke ponude. Prema tome, kompleksan proizvod banja Srbije, pored programa namenjenih lečenju i rehabilitaciji, sadržao bi i druge aktivnosti kako bi se obezbedio kvalitetan i autentičan doživljaj za turiste tokom boravka u destinaciji. Cilj ovog rada je da se na osnovu analize postojećeg stanja ukaže na mogućnost kreiranja kompleksnog proizvoda banja Srbije. U radu je izvršena i analiza turističkih proizvoda banja u okruženju, čiji bi model razvoja mogle da slede i srpske banje.
\end{abstract}

\section{Ključne reči:}

kompleksan turistički proizvod, banje, Srbija, destinacija, konkurentnost.

\section{UVOD}

Promene, kako na strani ponude tako i na strani tražnje, uslovile su neophodnost formiranja kompleksnog (integrisanog) turističkog proizvoda. Turističke proizvode karakteriše složena priroda. Sastoje se od brojnih komponenti, pri čemu svaka ima funkcionalnu ulogu u amalgamu materijalnih i nematerijalnih elemenata. Ove komponente se međusobno dopunjuju, jer svaka od njih obezbeđuje turisti deo ukupne vrednosti proizvoda (Koutoulas, 2004). Imajući u vidu veliki broj učesnika u razvoju turizma jedne destinacije i njihove ciljeve, turistički proizvod banja je potrebno obogatiti aktivnostima u očuvanom prirodnom ambijentu, ponudom gastronomskih specijaliteta, različitim sadržajima za odmor i rekreaciju, organizovanjem poseta i obilazaka kulturnim dobrima, manifestacionim sadržajem i sl. Kombinacija navedenih aktivnosti može biti osnova budućeg razvoja turizma banja. Cilj ovog rada je da, analizirajući resurse kojima banje Srbije raspolažu, ukaže na mogućnosti oblikovanja sadržajnijeg i bogatijeg turističkog proizvoda. Formiranje takvog proizvoda doprinelo bi da banje Srbije zauzmu mesto na evropskoj mapi banjskog i zdravstvenog turizma.

\section{Abstract:}

Tourism product formation is one of the most important tasks of the entities involved in shaping the tourism offer of a specific destination. Taking into account the constant changes in tourism demand, it is necessary to offer a product that could provide added value to tourists. In order to achieve competitiveness in the European market, Serbian spas are faced with the challenge of creating an integrated tourist offer. Therefore, besides the programs intended for treatment and rehabilitation, a complex product offered by spas in Serbia would also include other activities to ensure high-quality and authentic experience to tourists during their stay at the destination. Based on the analysis of the current situation, the paper aims to point out the possibilities for creation of the complex product of spas in Serbia. Furthermore, it analyzes spa tourism products in the neighbouring countries, whose development model could be used by spas in Serbia.

\section{Key words:}

complex tourism product, spas, Serbia, destination, competitiveness.

\section{POJAM TURISTIČKOG PROIZVODA}

Proizvod je sve ono što može biti ponuđeno na tržištu i što može da zadovolji želje ili potrebe potrošača (Kotler \& Keller, 2006). Polazeći od navedene definicije, uočavamo dominantnost opipljive dimenzije, što nije slučaj kod turističkog proizvoda. Imperativ u razvoju turističkog proizvoda je kreirati miks opipljivih i neopipljivih elemenata, koji neće samo zadovoljiti potrebe turista, već i prevazići njihova očekivanja. Turistički proizvod se može definisati kao skup elemenata (smeštaj, prevoz, atrakcije, događaji i dr.), koji su komplementarni i od kojih turista očekuje da mu obezbede iskustvo u destinaciji. Takva definicija proizvoda otvara pitanje koordinacije i saradnje između lokalnih preduzeća, koja obezbeđuju pojedinačne elemente turističkog proizvoda (Andergassen et al., 2013). Middleton i Clarke (2001) su prvi autori, koji su konstatovali da komponente turističkog proizvoda treba definisati sa stanovišta turista. Turisti smatraju da turistički proizvod obuhvata celokupno iskustvo od napuštanja mesta stalnog prebivališta do povratka u isto. Sa druge strane, turisti doživljavaju destinaciju kao jedinstvenu celinu, koja nudi integrisano iskustvo i proizvod, koji je 
zapravo sačinjen od proizvoda i resursa pojedinačnih aktera, čiji uspeh zavisi od efikasne koordinacije i povezivanja resursa (Haugland et al., 2011).

Dve bazične forme turističkog proizvoda su (Bakić, 2008):

- Parcijalni turistički proizvod, koji formiraju nosioci turističke ponude i na turističkom tržištu i njega nude kao sopstveni proizvod hotelijerska preduzeća, prevoznici, putničke agencije, ali i drugi učesnici na strani turističke ponude (muzeji, galerije, sportske institucije i sl.).

- Integrisani turistički proizvod je onaj proizvod kako ga percipira i konzurmira turista. Integrisani proizvod je zbir većeg ili manjeg broja različitih parcijalnih proizvoda.

Imajući u vidu činjenicu da turistički proizvod predstavlja sve ono što iz ugla turiste treba i može da zadovolji njegove potrebe, neophodno je ukazati na elemente, koje destinacije poseduju i koriste za kreiranje integrisanog turističkog proizvoda. Objedinjeni turistički proizvod predstavljao bi spoj sledećih elemenata (Popesku, 2013):

- Atraktivnost destinacije - obuhvata prirodne i društvene pogodnosti u okviru destinacije i bitno utiče na konkretan izbor destinacije.

- Uslovi za boravak i usluge u destinaciji - obuhvataju objekte za smeštaj i ishranu, kao i sve ostale pogodnosti, koje omogućavaju turistima boravak u destinaciji (lokalni transport, sportske aktivnosti, trgovina i ostale usluge).

- Pristupačnost destinacije - podrazumeva udaljenost destinacije u odnosu na emitivna tržišta i izražava se troškovima, brzinom i udobnošću dolaska do odredišta (infrastruktura, oprema, operativni faktori i državna regulativa u oblasti saobraćaja).

Grupa autora (McCabe et al., 2012) smatra da turisti očekuju integrisani turistički proizvod, koji im omogućava da znaju koje im aktivnosti stoje na raspolaganju u destinaciji (atrakcije, smeštaj, informacije, razmena iskustva, suveniri, i dr.). Razvoj takvog proizvoda zahteva dublje razumevanje turističkih potreba kako bi se turistima obezbedilo iskustvo tokom boravka u destinaciji. Kreiranje objedinjenog turističkog proizvoda je složen zadatak, zbog postojanja velikog broja učesnika, odnosno nosilaca turističke ponude, čije je parcijalne proizvode, ali i interese neophodno koordinirati i uskladiti. Krajnji cilj je realizacija ekonomske koristi od kreiranja i plasmana objedinjenog proizvoda, koja je zasnovana na satisfakciji potrošača. Turističke destinacije mogu biti tretirane kao proizvodi, jer predstavljaju tačku potrošnje kompleksa aktivnosti, koje turistima obezbeđuju iskustvo koje turističke agencije plasiraju na turističko tržište (Ashworth \& Goodall, 2013).

Konkurentnost turističkih destinacija zasniva se na činjenici da je iskustvo, koje turista stiče u destinaciji fundamentalni proizvod u turizmu. Cilj turističkog putovanja za svakog učesnika je postizanje željenih iskustava, odnosno osećanja izazvanih onim što je turista video i doživeo na destinaciji. Konkurentnost turističkih destinacija je povezana sa sposobnošću da se turisti obezbedi veće zadovoljstvo u odnosu na konkurentske destinacije (Popesku \& Pavlović, 2013). Polazeći od navedene definicije, kreiranje integrisanog turističkog proizvoda je osnova konkurentnosti turističkog mesta. Razvoj inovativnih turističkih proizvoda, koji uzimaju u obzir specifične potrebe datih tržišnih segmenta i koji pružaju jedinstveno turističko iskustvo, može značajno povećati konkurentnost destinacija. Za razliku od turističkih proizvoda razvijanih u prošlosti, koji su imali negativan uticaj na životnu sredinu, inovativni turistički proizvodi bi trebalo da ublaže postojeće probleme stavljajući akcenat na održivost sa ciljem izdvajanja od konkurencije (Custòdio-
Santos et al., 2014). Rastući zahtevi i očekivanja turista, pre samog putovanja, uslovili su objedinjavanje komplementarnih aktivnosti, koje određena destinacija može ponuditi, u jedinstven turistički proizvod. Ovako oblikovana turistička ponuda pružiće savremenim turistima, osim zdravstvenih lečilišnih usluga i autentičan doživljaj kome teže.

\section{ANALIZA KOMPLEKSNOSTI TURISTIČKIH PROIZVODA BANJA SRBIJE}

Osnovu razvoja banjskog turizma čine njeni prirodni i antropogeni resursi. Prirodne izvorne vrednosti ogledaju se u: povoljnom geografskom položaju, klimatskim predispozicijama, lekovitim mineralnim vodama, prirodnom ambijentu i raznovrsnom biljnom i životinjskom svetu. Imajući u vidu savremene tendencije na turističkom tržištu i kontinuirane promene u zahtevima turističke tražnje, prirodne i antropogene vrednosti nisu dovoljan preduslov za obezbeđivanje konkurentske prednosti i unapređivanja imidža banja Srbije na evropskom i međunarodnom nivou. U daljem radu, predmet analize su banje, koje imaju realnu mogućnost da na bazi postojećih resursa unaprede svoju ponudu i objedine ih u integrisani turistički proizvod.

Vrnjačka Banja predstavlja primer dobre prakse sa aspekta kvaliteta i strukture turističkih proizvoda. U ponudi jednog od najpoznatijih i najposećenijih banjskih lečilišta Republike Srbije, zastupljen je veliki broj turističkih proizvoda. Fokus turističkog razvoja Vrnjačke Banje predstavljaju:

- Zdravstveni turizam - Zahvaljujući lekovitosti izvora termomineralnih voda i klimatskim karakteristikama, Vrnjačka Banja je od nekadašnjeg lečilišta postala savremeni zdravstveni centar, koji objedinjuje tradicionalne i savremene metode lečenja i prevencije. Nosilac razvoja zdravstvenog turizma je Specijalna bolnica Merkur, koja predstavlja najsavremeniji centar za dijagnostiku, prevenciju, lečenje i rehabilitaciju bolesti organa za varenje i šećerne bolesti. Raspolaže savremenom medicinskom službom sa 50 lekara od toga 44 specijalista i subspecijalista raznih specijalnosti, objektima za smeštaj posetilaca preko cele godine (Vrnjačka Banja, 2014). Pored lečilišne funkcije, Specijalna bolnica Merkur je primarni nosilac razvoja spa \& wellness turizma u Vrnjačkoj Banji. Merkur poseduje nekoliko objekata, koji čine zaokruženu celinu: Wellness centar Fons Romanus, Aqua centar Waterfall, Fitness centar Merkur Gym i Peloid centar Limus Romanus (Ruđinčanin \& Topalović, 2008). Merkur je jedinstvena zdravstvena ustanova, koja u svom programu objedinjuje medicinske usluge i spa \& wellnes program. Od početka XXI veka pa do danas, rukovodstvo i menadžment Merkura kontinuirano inovira i ulaže u sopstveni paket usluga. Kvalitet usluga se ne može osporiti, jer je potvrđen nizom nagrada na nacionalnom, ali i na međunarodnom nivou. Pored Specijalne bolnice Merkur, u Vrnjačkoj Banji postoji niz manjih smeštajnih objekata, koji u svojoj ponudi poseduju spa \& wellness centre.

- Sportsko-rekreativni turizam - Vrnjačka Banja ima dugu tradiciju u razvoju sportsko-rekreativnog turizma. Banja je često domaćin sportskim ekipama kada su u pitanju pripreme, ali isto tako i domaćin takmičenja (rukomet, plivanje, košarka i sl.). Jedan od glavnih lokaliteta je Sportski centar Raj. Ovaj kompleks predstavlja glavni sportsko-rekreativni prostor Vrnjačke Banje i sadrži: sportski centar, teniski centar i jahački centar. Sportski centar obuhvata aktivnosti fudbala, atletike i malih sportova, sa univerzalnom sportskom salom i sportskim selom (Opština Vrnjačka Banja, 2010). Pored savreme- 
ne hale sportova, u Vrnjačkoj Banji postoje tri travnata fudbalska terena, betonska atletska staza, stadion malih sportova Kocka, otvoreni betonski tereni za mali fudbal, rukomet i košarku, fiskulturne sale za košarku, odbojku i rukomet sala za stoni tenis, kao i otvoreni i zatvoreni bazeni (Opština Vrnjačka Banja, 2010).

- Manifestacioni turizam - Od osnivanja, Vrnjačka Banja je poznata po karnevalima, zabavama, balovima i sl. Svake godine se održi veliki broj manifestacija, koje privlače domaće i inostrane goste. Jedna od najznačajnijih kulturnih manifestacija u Srbiji pod nazivom $\mathrm{Vr}$ njačke kulturne svečanosti traje 100 letnjih dana, a čini je program iz oblasti književnosti, pozorišnog, filmskog, televizijskog, muzičkog stvaralaštva, likovne delatnosti, izdavaštva i muzeologije. Vrnjačke kulturne svečanosti obuhvataju: Međunarodni festival klasične muzike; Književno leto; Pozorišne dane srpskog teatra, Festival likovnog stvaralaštva; Festival filmskog scenarija i dr (Vrnjačka Banja, 2014). Vrnjačka Banja je poznata i po sledećim manifestacijama: Vrnjački Karneval, Dani Danila Bate Stojkovića, Love fest, Poljubi me na mostu ljubavi, Na Desankin dan i dr.

- Kongresni turizam - Najzastupljeniji oblik poslovnog turizma u Vrnjačkoj Banji je kongresni turizam. Intenzivan razvoj poslovnog turizma počinje nakon izgradnje Kongresnog centra hotela Zvezda 1980. godine, kada je Banja dobila pravi kongresni prostor za održavanje velikih skupova (Ruđinčanin \& Topalović, 2008). Najdužu tradiciju u razvoju ovog vida turizma ima hotel Zvezda. Jedinstven je po kongresnom centru, koji je drugi po veličini posle Sava Centra (Podovac \& Milićević, 2013). Organizacijom poslovnih događaja bavi se veći broj hotela, koji u poređenju sa hotelom Zvezda imaju znatno manje kapacitete, ali su savremeno opremljeni.

- Kulturno-istorijski turizam - Vrnjačka Banja poseduje bogato i reprezentativno kulturno nasleđe, čiji je snažan kulturni identitet zasnovan na arheološkom nasleđu, lokalitetima kulturno-istorijskog nasleđa, umetničkim delima, institucijama kulture, velikom broju manifestacija, tradicionalnim vrednostima i načinu života lokalnog stanovništva. Najstariji tragovi naseljavanja u ovoj oblasti potiču iz mlađeg kamenog doba, iz perioda od 3800. do 3100. godine pre nove ere, odnosno sa kraja neolita i početka eneolita (Borović-Dimić \& Dimić, 2003). Razvoj današnje Vrnjačke Banje započet je 1868. god. kada je osnovano udruženje Osnovatelno fundatorsko društvo kiselo-vruće vode na inicijativu Pavla Mutavdžića (Ruđinčanin \& Topalović, 2008). Jedan od najstarijih i najautentičnijih pseudo-klasicističkih objekata je Zamak Belimarković. Prema projektu bečkog arhitekte Vintera, u periodu između 1882. i 1887. god. Izgrađen je dvorac za generala Jovana Belimarković, tadašnjeg ministra srpskog kralja Milana Obrenovića i namesnika maloletnog kralja Aleksandra Obrenovića. Zamak Belimarković predstavlja kulturno dobro od neprocenjive vrednosti za Vrnjačku Banju. Danas nosi naziv Zamak kulture i u njemu je smešten Zavičajni muzej, u kome se održavaju književne večeri, izložbe, stalne postavke arheološke građe i sl. U banjskom parku postoji veliki broj spomen obeležja (spomen-biste, spomen-česme, skulpture, spomen-ploče i dr.), koja su povezana sa značajnim istorijskim događajima.

Sokobanja - Tradicija i kontinuirani razvoj uslovili su da Sokobanja zauzme veoma značajno mesto u banjskom turizmu Srbije. Termomineralni izvori Sokobanje čine primarne resurse, koji u osnovi određuju zdravstveno-lečilišnu funkciju banje i čine okosnicu razvoja turizma (Jovanović \& Radivojević, 2006).

- Zdravstveni turizam - Sokobanja ima dugu tradiciju razvoja zdravstvenog turizma. Za lekovitost njenih izvora znalo se još u doba Rimljana. Kontinentalna klima, visoka koncentracija kiseonika, ozona i negativnih jona u vazduhu, nezagađenost, prisustvo specifičnih elemenata u vazduhu i oligomineralnim vodama su glavni razlozi zbog kojih je Sokobanja danas jedan od najznačajnijih zdravstvenih centara Srbije. Nosilac razvoja zdravstvenog turizma je Specijalna bolnica Sokobanja, koja pruža usluge dijagnostike, lečenja i rehabilitacije bolesti disajnih organa kod dece i odraslih. U cilju upotpunjavanja ponude za turiste, koji ne dolaze isključivo zbog lečenja, na raspolaganju su spa \& wellness usluge u vidu masaža, sauna, slane sobe i fitnes programa (Sokobanja, 2014).

- Lovni turizam - Blizina planina Ozren, Rtanj i Devica omogućuju, osim oblikovanja ponude planinskog turizma, i komplementarnost sa lovnim turizmom. Na ovim prostorima nalaze se brojna staništa različitih divljači: vuk, srna, divlja svinja, lisica, fazan, jarebica, divlji golub, divlja patka. Osim lova na divljač, moguće je organizovati i sportski ribolovni turizam, zahvaljujući blizini reke Moravice i Bovanskog jezera (Sokobanja Travel, 2014).

- Kulturno-istorijski turizam - Sokobanja i okolina su veoma bogati kulturnim dobrima kojima je moguće obogatiti turističku ponudu. Jedno od najatraktivnijih kulturnih dobara za turiste je Sokograd - tvrđava iz doba Rimljana (I vek p. n. e.). Osim svoje istorijske vrednosti, ovo dobro je veoma značajno kao deo turističke ponude, jer je smešteno u ekološki očuvanom ambijentu. Ostaci antike na teritoriji Sokobanje su brojni. Najznačajniji su Tetomirov grad, Rujevica, Trubarevačko gradište, Latinski grad i Lipov trap (Jovanović \& Radivojević, 2006). Ponudu je moguće obogatiti i posetom turskom kupatilu Amam, koje je koristio i knez Miloš Obrenović, kao i manastiru Svetog Aranđela.

- Sportsko-rekreativni turizam - Sokobanja raspolaže povoljnim prirodnim predispozicijama, koje obezbeđuju adekvatan ambijent za sportske aktivnosti. Sportsko-rekreativni kapaciteti obuhvataju: fudbalski stadion kapaciteta 1500 gledalaca, igrališta za fudbal, terene za male sportove, zatvorene bazene, terene za tenis, streljanu, kuglanu, trim staze i dr. Planine kao što su Ozren, Rtanj i Devica pružaju mogućnosti za ekstremne sportove kao što je paraglajding (Sokobanja, 2014 a).

- Manifestacioni turizam - Turističke manifestacije održavaju se u letnjem periodu za vreme banjskog Kulturnog leta. Najpoznatije manifestacije su internacionalni festival Prva harmonika Sokobanje, zatim međunarodna manifestacija salon ekološke karikature i umetnička kolonija Sokograd, tradicionalna manifestacija Zlatne ruke, koja se ogleda u takmičenju u pripremanju tradicionalnih jela, narodnih rukotvorina i veštinama zanata (Banje u Srbiji, 2014).

- Wellness turizam - Kako bi se banjska turistička ponuda prilagodila zahtevima mlađe populacije, što je i trend u banjama u Evropi, u Sokobanji je na obali reke Moravice otvoren Wellness centar Soko Terme. Centar raspolaže sa dva zatvorena i jednim otvorenim bazenom. Voda je termo-mineralna, temperature od $39^{\circ} \mathrm{C}$ stepeni i sadrži radon.

$\mathrm{Na}$ osnovu svega navedenog, zaključujemo da analizirane banje imaju dugu tradiciju u razvoju turizma zahvaljujući bogatstvu prirodnih i antropogenih resursa. Sa druge strane, moramo uvažiti i trend odlaska turista u banje i to ne isključivo zbog 
lečenja i rehabilitacije. Postojanje tržišne niše, koja posećuje banje zbog aktivnog odmora, uslovljava redefinisanje koncepta razvoja banja Srbije. Osnovu za dalji razvoj turizma u banjama Srbije bi trebalo zasnivati na formiranju integrisanog turističkog proizvoda i komplementarnom povezivanju više vidova turizma: zdravstvenog, wellness, planinskog, izletničkog, kongresnog, sportsko-manifestacionog, ekološkog. Kako bi se realizovali ekonomski efekti i postigla bolja konkurentska pozicija na turističkom tržištu, nosioci razvoja turizma banja Srbije moraju pronaći način da postojeće proizvode oplemene atraktivnim sadržajima i da parcijalne proizvode objedine $u$ integrisani proizvod sa ciljem zadovoljenja različitih potreba turista.

\section{OSNOVNE KARAKTERISTIKE TURISTIČKIH PROIZVODA BANJA U OKRUŽENJU}

$\mathrm{U}$ radu je izvršena analiza turističkih proizvoda banja $\mathrm{u}$ okruženju, koje predstavljaju i glavne konkurente. Predmet analize su banje, koje su uspele da uz korišćenje postojećih resursa, kreativnost, inovativnost i praćenje tendencija u razvoju turizma, obezbede turistima celokupan doživljaj tokom boravka.

Karlove Vari su jedno od najpoznatijih banjskih lečilišta u Češkoj. Nalaze se na udaljenosti od 120 kilometara zapadno od Praga (Karlovy Vary, 2014). Od 79 izvora termomineralne vode koristi se 13 izvora za piće i lečenje. Mineralne vode su slične prema svom sastavu, ali zbog različitih temperatura i količine ugljendioksida imaju različite efekte. Karlove Vari poseduju veliki broj parkova jedinstvene prirodne arhitekture, u kojima se nalaze brojni spomenici i organizuju događaji različitog karaktera. Karlove Vari poseduju veliki broj lokaliteta kulturno-istorijskog nasleđa, među kojima su: muzeji, verski objekti, galerije, osmatračnice, kolonade i dr. Najpoznatiji lokaliteti kulturno-istorijskog nasleđa su: Muzej zlatnog ključa, Moserov muzej stakla, crkva Marija Magdalene, kula Dijana, vidikovac Gete, dvorac Kula, opštinsko pozorište, Nacionalna kuća Karlove Vari. Banja je domaćin velikog broja događaja kulturnog i sportskog karaktera, među kojima su: Međunarodni festival filma, festival porcelana, festival hrane, festival Jazzfest, takmičenje u triatlonu i dr. (Karlovy Vary, 2014 a). Kompleksnost turističkog proizvoda Karlovih Vari ogleda sa u činjenicama da svaki hotel poseduje bazene, medicinske tretmane, razvijenu spa \& wellneess ponudu, sportsko-rekreativni sadržaj, višenamenske i konferencijske sale i prostorije različitih kapaciteta i dr. (Ministarstvo trgovine turizma i usluga, 2007).

Terme Čatež se nalaze između dve reke Save i Krke, u podnožju planine Gorjanci, na 8 kilometara od granice sa $\mathrm{Hr}$ vatskom i na samo 430 kilometara od Beograda. Predstavljaju jedan je od vodećih termalno-turističkih centara u Sloveniji sa bogatom ponudom i programima na vodi. Zahvataju površinu od $13.000 \mathrm{~m}^{2}$, i na tom prostoru raspoređeno je 10 bazena sa termalnom vodom čija se temperatura kreće između 26 i 36 ${ }^{\circ} \mathrm{C}$. Pored vodenih programa rekreacije, terme nude i kvalitetan smeštaj i uslugu u mnogobrojnim hotelima kao i aktivan odmor u sportskom rekreativnom centru, golf terene u Mokricama; za ljubitelje kocke na raspologanju je i „Grand Casino Lido Terme Čatež“. Ponuda proizvoda na turističkom području terme Čatež obuhvata (Terme Čatež, 2014):

- Letnja termalna rivijera (adrenalinska trojka tobogan, zabavni park sa bandži trambolinama i bazenom sa električnim čamcima, piratsko ostrvo, dečiji vodeni park sa spravama za decu, 450-metarska spora reka, olimpijski bazen, bazeni sa podvodnim masažerima, dečiji bazeni, bazen sa virpulovima, brzim tokom, veštačko jezero, dodatna zabava (vožnja sa automobilčićima, mini golf, tramboline, odbojka na pesku).
- Zimska termalna rivijera ima ispod dve kupole više od $1.800 \mathrm{~m}^{2}$ pokrivenih termalnih vodenih površina (baze nepravilnih oblika sa virpulovima, vodopadima, brzom rekom, masažnim ležištima, toboganom, i sa prelaskom u spoljašnji bazen, dečiji bazen, drvo doživljaja, bazen sa talasima, potočići, ručne masaže, restoran i bistro, terasa i livada za sunčanje).

- Sauna park (kristalna sauna, parna sauna, ekstremna sauna, indijska sauna, slana sauna, infracrvena sauna, finska aroma sauna, aquaviva sauna).

- Centar zdravlja i lepote (unutrašnji i spoljašnji bazen sa termalnom vodom, masažna ležišta, virpulovi i podvodna kupka, finska sauna i turska kupka, rimsko-irske kupke, fitnes studio, solarijum, kozmetički salon, prostorije za terapiju i individualne ručne tehnike (masaža, limfna drenaža i refleksno-zonska masaža stopala, hidroterapija, kineziterapija, eletroterapija, termoterapija) i individulane medicinske usluge.

- U hotelu „Terme“ postoje 4 konferencijske sale, koje se mogu spojiti (po 200 osoba); hotel „Mokrice“ ima 2 konferencijske sale (40 i 60 osoba); hotel „Toplice“ ima jednu konferencijsku salu (kapacitet 900 osoba); i hotel "Čatež“ ima jednu salu (kapacitet 100 osoba).

- Sportski centar (tenisko igralište u klimatizovanoj dvorani i 6 peščanih teniskih igrališta uz dvoranu, squash, bowlingm fitness, stoni tenis, igralište za badminton, betonsko igralište za fudbal, rukomet i košarku, biciklističke staze, šetališta, teren za golf).

Finansijska sredstva Evropske unije, donacije i naplata poreza ili prodaja sirovina kojima raspolažu, uslovila su da analizirane destinacije ostvaruju značajne rezultate na turističkom tržištu. Karlove Vari i Terme Čatež predstavljaju primere banja, koje su od ruralnih i zaostalih sredina, u kojima je dominirala agrokultura, postale destinacije koje privlače veliki broj domaćih i stranih turista. Analizirane banje su objedinile proizvod zdravstvenog, spa \& wellness i poslovnog turizma. Za privlačenje inostrane turističke tražnje obezbedile su velike vodene površine sa tematskim sadržajima, upotpunile spa \& wellness ponudu savremenim oblicima relaksacije i ulepšavanja, dopunile sportsko-rekreativne sadržaje kako bi obezbedile mogućnosti za permanentnu ispunjenost boravka turiste u destinaciji. Osim pomenutih inovacija u razvoju turističkog proizvoda, vode agresivnu promocionu politiku, pronalaze nove načine distribucije turističkog proizvoda i teže izgradnji dugoročno konkurentnog i prepoznatljivog brenda njihovih banja. Banje u okruženju se nisu oslonile isključivo na prirodni potencijal, već su uložile velike napore kako bi osmislile i formirale kompleksniji i sadržajniji proizvod koji bi bio prihvaćen od strane savremenog turiste.

\section{ZAKLJUČAK}

Prirodni i antropogeni potencijal banja Srbije je ogroman. Zbog toga je neophodno oblikovati integrisani proizvod, koji će zadovoljiti potrebe sofisticiranog turiste koji želi da uči, upoznaje druge kulture, provodi aktivno svoj odmor i koji zahvaljujući digitalnim sredstvima marketing komunikacije veoma lako može doći do detaljnih opisa željene turističke destinacije. Nosioci ponude banja suočavaju se sa velikim izazovom: s jedne strane njihova ciljna grupa su bolesnici kojima će ponuditi zdravstvene usluge, a sa druge strane savremeni turisti u potrazi za aktivnim odmorom i ravnotežom duha i tela. Najpre je potrebno jasno razgraničiti ponudu zdravstvenog i spa \& wellness turizma, a zatim i dodati vrednost ponudi obogaćivanjem sadržajima u vidu kulturnog, verskog, gastronomskog sadržaja i dr. 
Banje Srbije su zatvorene u svom okruženju i njihovi vidici su, kada je reč o inoviranju postojećeg proizvoda, prilično suženi. Izlazak na evropsko, ali i na međunarodno turističko tržište, gde je već zastupljen veliki broj konkurenata, moguć je isključivo uz postojanje jedinstvenog proizvoda, koji će biti kvalitetan, drugačiji od ostalih i koji će pružiti odgovarajuću vrednost za novac. Kako bi proizvod banja Srbije objedinio sve aktivnosti za kvalitetan doživljaj turista, neophodno je proširiti tradicionalne okvire formiranja ponude i proizvod kreirati iz ugla samog turiste, koji je željan novih iskustava.

\section{LITERATURA}

Andergassen, R., Candela, G., \& Figini, P. (2013). An Economic Model for Tourism Destinations: Product Sophistication and Price Coordination. Tourism Management, 37, 86-98. DOI: 10.1016/j.tourman.2012.10.013

Ashworth, G., \& Goodall, B., (2013). Marketing Tourism Places. Abingdon, Oxon: Routledge.

Bakić, O. (2008). Marketing u turizmu. Sremska Kamenica: Fakultet za uslužni biznis.

Borović-Dimić, J., \& Dimić, B. (2003). Vrnjačka Banja na starim razglednicama. Vrnjačka Banja: Zavičajni muzej-Zamak kulture, Kulturni centar Vrnjačke Banje.

Custòdio Santos, M., Ferreira, A. M., \& Costa, C., (2014). Influential factors in the competitiveness of mature tourism destinations. Tourism \& Management Studies, 10(1), 73-81.

Haugland, S. A., Ness, H., Grønseth, B. O., \& Aarstad, J. (2011). Development of tourism destinations: An integrated multilevel perspective. Annals of Tourism Research, 38(1), 268269. DOI: 10.1016/j.annals.2010.08.008

Jovanović, J., \& Radivojević, A. (2006). Turističko-geografski prikaz Sokobanje. Glasnik Srpskog geografskog društva, LXXXVI (2), 287-299.

Karlovy Vary. (2014 a). Introducing Karlovy Vary. Dostupno na http://www.karlovy-vary.cz/en/about-karlovy-vary/introducing-karlovy-vary. 18.06.2014.

Karlovy Vary. (2014). Karlovy Vary. Dostupno na http://www. karlovy-vary.cz/en/ 18.06.2014.

Kotler, K., \& Keller L. K. (2006). Marketing menadžment. Beograd: Data Status.
Koutotoulas, D. (2004). Understanding the Tourism Product, Interim symposium of the Research Committee on International Tourism (RC 50) of the International Sociological Association (ISA), Understanding Tourism -Theoritecal Advances, 14-16 May 2004, pp. 1-22. Greece: University of the Aegean, Mytilini.

McCabe, S., Sharples, M., \& Foster, C. (2012). Stakeholder engagement in the design of scenarios of technology-enhanced tourism services. Tourism Management Perspectives, 4, 36-44. DOI: 10.1016/j.tmp.2012.04.007

Middleton, V., \& Clarke, R. J. (2001). Marketing in Travel and Tourism. Oxford: Butterworth-Heinemann.

Ministarstvo trgovine turizma i usluga. (2007). Sokobanja: Master plan turističke destinacije. Dostupno na http://www. opstinasokobanja.com/Dokumenta/Strategija-Master\%20 plan/sokobanja_masterplan_turisticke_destinacije.pdf 18.06.2014.

Opština Vrnjačka Banja. (2010). Regionalni centar za životnu sredinu za centralnu i istočnu Evropu, kancelarija u Srbiji, Lokalni ekološki akcioni plan, Vrnjačka Banja/Beograd.

Podovac. M., \& Milićević, S. (2013). Potencijali Srbije za razvoj poslovnog turizma. Ekonomski pogledi, 31(1), 35-48.

Popesku, J. (2013). Marketing u turizmu i hotelijerstvu. Beograd: Univerzitet Singidunum.

Popesku, J., \& Pavlović, D. (2013). Competitiveness of Serbia as a tourist destination: Analysis of selected key indicators. Marketing, 44(3), 199-210.

Ruđinčanin, O., \& Topalović, O. (2008). Vrnjačka Banja na početku XXI veka. Vrnjačka Banja: Biblioteka Dr Dušan Radić.

Sokobanja Travel. (2014). Biogeografske vrednosti Sokobanje. Dostupno na http://www.sokobanja.travel/sokobanja/geografski-polozaj/biogeografske-vrednosti. 19.06.2014.

Sokobanja. (2014 a). Sportsko-rekreativni turizam. Dostupno na http://www.sokobanja.org.rs/sr/sportsko-rekreativni-turizam/tekst. 11.12.2014.

Sokobanja. (2014). Specijalna bolnica Sokobanja. Dostupno na www.soko-banja.rs 01.06.2014

Terme Čatež. (2014). Terme Čatež Slovenija. Dostupno na http:// www.terme-catez.si/en/ 18.06.2014.

Vrnjačka Banja. (2014). Specijalna bolnica Merkur. Dostupno na http://www.vrnjackabanja.co.rs/srpski/sadrzaj/zdravljeglmeni/specijalnabolnicaglmeni. 01.06.2014. 